\title{
Ozone Risk Assessment for European Vegetation
}

\author{
Massimo Fagnano*, Albino Maggio \\ Dipartimento di Ingegneria Agraria e Agronomia del Territorio, Università di Napoli Federico II \\ Via Università 100, 890055 Portici (NA), Italy
}

Received: 16 January 2008. Accepted 21 January 2008.

Tropospheric ozone is the most critical air pollutant for plants. In recent years, common research goals have brought together different groups working on plant/ozone interactions, interested in establishing a European network that could efficiently make progress in this important research area. In this context, the international workshop on "Ozone risk assessment for European vegetation" was held on May 1011, 2007 in Capri (Naples, Italy). This was one of the activities promoted by the steering group of the Ozone Risk Assessment Network established in Ispra on February 23-24, 2006. During the Capri workshop, different facets of ozone effects on three major types of European vegetation, crops, grasslands (semi-natural vegetation) and forests, were discussed. The conclusions of the three working-groups, who contributed to a discussion focussed on methodological problems and research needs, are briefly summarized in the following sections. We refer to the contributions reported in this special issue of the Italian Journal of Agronomy for a detailed analysis of specific aspects.

\section{Crops}

1. There is evidence of an increase in global background ozone concentrations, which may lead to significant changes in regional ozone exposures in the future.

2. Croplands and permanent pastures (i.e. semi-natural vegetation) are a structural factor of the European landscape, since they cover $47 \%$ of the total land area of EU27. Ozone pollution could adversely affect the different functions of these agro-ecosystems with significant effects on European environments.

3. Ozone can directly affect farm economic performance by lowering yield quantity and quality and indirectly by reducing crop water use efficiency (WUE). In addition, it may enhance the effect of other factors that already cause problems to agriculture (i.e. economic farm sustainability; effects of climate changes that may cause water shortage). Therefore, ozone can contribute to agriculture abandonment, with consequent social and economic problems (increasing depopulation of marginal areas and increasing urbanization) and deterioration of landscape quality (loss of cultural identity).

4. Ozone can increase $\mathrm{C}$ losses from different cropping systems, since it reduces the Net Primary Production (NPP) and the Net C Exchange (NCE) and also $\mathrm{C}$ return to the soil (crops residues). The increase of oxidizing capacity of the atmosphere could also increase the soil organic matter (SOM) oxidation and $\mathrm{CO}_{2}$ emissions from the soil.

5. Ozone can increase both the crop nitrate loss and the ground water nitrate pollution. Since ozone reduces crop growth, it also reduces $\mathrm{N}$ uptake from the soil, $\mathrm{C}$ return to the soil and the $\mathrm{C} / \mathrm{N}$ of crop residues, with a consequent decrease of the soil $\mathrm{C} / \mathrm{N}$ ratio and SOM humification levels.

6. Critical effects of ozone for vegetation and crop yield loss have been indicated by the EU (Council Directive on air pollution by ozone - 92/72/EEC). Nevertheless, the as-

\footnotetext{
* Corresponding Author: Tel.: +39 081 2539129. E-mail address: fagnano@unina.it
} 
sessment of quantitative dose/response relationships refers to a concentration based approach.

7. Plant responses to ozone pollution are associated with the actual amount of ozone absorbed by the plants, rather than with exposure levels, as currently stated by the EU Directive. Different types of stress will antagonistically/synergistically interact to eventually affect plant metabolism, growth and yield. Water deficit, saline and temperature stresses reduce stomatal conductance and thus the dose of ozone absorbed by the plants.

8. A flux-based approach that considers all the factors that reduce ozone uptake by plants, is necessary to gain realistic dose/response relationships under the typical conditions of different cropping systems at European scale.

Contributors to the CROP working group: $M$. Fagnano and A. Maggio, Naples (Italy); G. Mills, Bangor (United Kingdom); L. Grünhage, Giessen (Germany); M. Badiani, Reggio Calabria (Italy); A. Ranieri, Pisa (Italy); C.J. Saitanis, Athens (Greece); G. Gerosa, Brescia (Italy); J. Bender, Braunschweig (Germany); M. Vitale, Rome (Italy); P. Dizengremel and D. Le Thiec INRA, Nancy (France); A. De Marco, ENEA Rome (Italy).

\section{Grassland}

1. Permanent pastures occupy about $10 \%$ of the land area of Europe, and semi-natural grasslands occupy a further $3 \%$ of the land area; most of the latter support low-intensity agriculture, and are not actively managed (e.g. reseeded annually). Many of these sites are actively conserved for their biodiversity.

2. European grasslands are a major sink for carbon dioxide from the atmosphere. The net biome productivity per unit area (carbon sink) for grasslands is around $2 / 3$ of forests, and soils under permanent grassland act as a significant carbon reservoir. Ozone has the potential to change species composition, leading to changes in biodiversity and grazing or fodder quality, and to change the proportion of plant material between shoots and roots, and the amount of carbon stored in soils.

3. Although there has been much research over the past 30 years on the effects of ozone on plants, this has focussed on agricultural crops and forest tree species, and experiments have been targeted at single species or cultivars. Semi-natural grasslands comprise a complex community of grasses and wildflower species, on which depend many invertebrates, birds and small mammals. We know that the effects of ozone on such communities cannot be predicted from studies on individual component species. Therefore the techniques for risk assessment that have been developed for crops and forest trees (AOT40 or ozone flux) cannot be used directly to assess the risk to grasslands.

4. It is therefore critical to build knowledge on existing field-based studies across Europe, in which grassland communities are exposed to ozone under ambient field conditions, in order to develop a method for assessing the risk posed by increasing ozone concentrations to communities of species-rich grasslands. Once the risk has been established, the long-term implications for biodiversity, nature conservation, sustainability and low-intensity agriculture can be assessed, and appropriate mitigation measures identified.

Contributors to the GRASSLAND working group: J.N. Cape, Midlothian (United Kingdom); J. Fuhrer, Zurich (Switzerland); G. Gerosa, Milan (Italy); L. Grünhage, Giessen (Germany); S. Manninen, Helsinki (Finland); B. Gimeno and R. Alonso, Madrid (Spain).

\section{Forest}

1. The Forest Group agreed that the exposurebased AOTx concept currently employed in the $\mathrm{O}_{3}$ risk assessment of forest systems needs to be replaced by a mechanistic, causeeffect related and, hence, phytomedically relevant approach. Evidence has increased that exposure-based analysis arrives at unreliable conclusions about $\mathrm{O}_{3}$ risk, in particular under water and light limitation, as the uptake of ozone as the noxious agent into the plant (i.e. the $\mathrm{O}_{3}$ dose) rather than the external $\mathrm{O}_{3}$ concentration of the ambient air drives plant responses. Risk assessment needs to be based, therefore, on a process-related understanding of both the influx of ozone 
through stomata into the leaf and the "physiologically effective" dose upon $\mathrm{O}_{3}$ uptake (i.e. responsiveness per unit of $\mathrm{O}_{3}$ uptake) hence, principles of $\mathrm{O}_{3}$ stress avoidance and tolerance, respectively.

2. From a methodological perspective, this approach requires intensified analysis on $\mathrm{O}_{3}$ sensitive tree species (e.g. fast-growing pioneers) growing in stands/plantations, wholeplant and stand-level approaches along with long-term perspectives and focus, in particular, on hormonal relationships, molecular control, ecophysiological performance, resource allocation and below-ground processes. Experimental free-air $\mathrm{O}_{3}$ release systems in the field will be the ultimate tool for achieving this task.

3. $\mathrm{O}_{3}$ risk analysis must not overlook interactions with other pollutants (in particular, nitrogen deposition), climatic, edaphic and topographic factors (temperature and moisture regimes) and the increasing $\mathrm{CO}_{2}$ concentration of the atmosphere. It was recommended to compare case studies based on free-air $\mathrm{O}_{3}$ release experimentation under their specific site scenarios (including pollution regimes) across the major geographical regions by means of a pan-European approach so that the ecological range and context of $\mathrm{O}_{3}$ stress in trees can be evaluated in an integrative way.

4. The issue of $\mathrm{O}_{3}$ impact on vegetation should be viewed in the context of human health to enhance political interest in risks by tropospheric ozone, to widen the perspective towards "environmental health" in general, and to increase the socio-economic appreciation of intact "ecosystem services" for wellbeing. In this context, also the effects of the vegetation on tropospheric $\mathrm{O}_{3}$ regimes (e.g. through gaseous exhalations from plants, land-use changes, species associations in forests) require attention.

5. It was stressed that risk assessment pursued each by the "forest", "crops" and "semi-natural vegetation" groups need to define joint conceptual interfaces, as at the landscape level $\mathrm{O}_{3}$ risks related to each of these vegetation types need to be integrated through modelling into one common assessment approach.

6. It was agreed that $\mathrm{O}_{3}$ risk assessment must nowadays extend beyond estimations of yield losses, rather probability evaluations of $\mathrm{O}_{3}$-induced injuries and damages as well as environmental/ecological changes in a wider context need to be covered. This is a pre-requisite for coping with an increasing demand for liability assessments in a legal context. These needs, as well as tropospheric ozone as a component of "Global Change", productivity of renewable resources through agroforestry and post-Kyoto policies, require an enhanced precision in $\mathrm{O}_{3}$ risk assessment, which is viable only through increased mechanistic understanding of $\mathrm{O}_{3}$ uptake into and uptake-related sensitivity of trees and forests or tree plantations.

7. Policy-relevant deliverables of potential new research projects need to replace the AOTx concept with novel, mechanistic $\mathrm{O}_{3}$ fluxbased modelling tools for risk assessment, which are ready for use in practice on a routine basis and which offer scientifically reliable evaluations of the probability and plausibility of $\mathrm{O}_{3}$-caused injuries, damages or other ecologically relevant alterations in woody-plant systems.

Contributors to the FOREST working group: R. Matyssek, Freising (Germany); M. Badiani, Reggio Calabria (Italy); S. Braun, Schönenbuch (Switzerland); J. Cermak, Brno (Czech Republic); S. Cieslik, Ispra (Italy); P. Cudlin, České Budějovice (Czech Republik); D. Ernst, München, (Germany); P. Dizengremel, Nancy (France); L. Emberson, York, (GB); M. Ferretti, (Italy); G. Gerosa, Brescia (Italy); Y. Jovilet, Nancy (France); A.H. Legge, Calgary (Canada); F. Loreto, Rome (Italy); D. Le Thiec, Nancy (France); T. Mikkelsen, Risoe (Danmark); W. Oßwald, Freising (Germany); E. Paoletti, Florence (Italy); A. Raineri, (Italy); M. Schaub, Birmersdorf (Switzerland); G. Wieser, Innsbruck (Austria); M. Zapletal, Opava (Czech Republik). 